\title{
Sensitizing TRAIL-resistant A549 lung cancer cells and enhancing TRAIL-induced apoptosis with the antidepressant amitriptyline
}

\author{
K.M.A. ZINNAH ${ }^{1,2}$ and SANG-YOUEL PARK ${ }^{1}$ \\ ${ }^{1}$ Biosafety Research Institute, College of Veterinary Medicine, Jeonbuk National University, Iksan, Jeonbuk 54596, \\ Republic of Korea; ${ }^{2}$ Department of Animal and Fish Biotechnology, Faculty of Biotechnology and Genetic Engineering, \\ Sylhet Agricultural University, Sylhet 3100, People's Republic of Bangladesh
}

Received December 14, 2020; Accepted April 16, 2021

DOI: $10.3892 /$ or.2021.8095

\begin{abstract}
Tumor necrosis factor-related apoptosis-inducing ligand (TRAIL) is a cytokine with the potential to induce cancer cell-specific apoptosis with minimal toxicity to normal cells. Therefore, the resistance of certain cancer cells to TRAIL is a major concern and agents that can either enhance TRAIL capabilities or overcome TRAIL resistance are necessary for the development of cancer treatments. The present study investigated whether the antidepressant drug amitriptyline could sensitize TRAIL-resistant A549 lung cancer cells and enhance TRAIL-induced apoptosis. Antidepressants are usually prescribed to cancer patients to relieve emotional distress, such as depression or dysthymia. The present study revealed for the first time, to the best of our knowledge, that amitriptyline increased death receptor (DR) 4 and 5 expression, a requirement for TRAIL-induced cell death. Genetic inhibitors of DR4 and DR5 significantly reduced amitriptyline-enhanced TRAIL-mediated apoptosis. Additionally, the present study explored whether blocking autophagy increased DR4 and DR5 expression. Blocking autophagy flux with the final stage autophagy inhibitor chloroquine (CQ) also upregulated DR4 and DR5 expression. TRAIL in combination with amitriptyline or CQ significantly increased the expression of apoptosis-indicator proteins cleaved caspase- 8 and caspase-3. The expression levels of LC3-II and p62 were significantly higher in amitriptyline-treated cells, which confirmed that amitriptyline blocks autophagy by inhibiting the fusion of autophagosomes with lysosomes. Overall, the present results contributed to understanding the mechanism responsible for the synergistic anticancer effect of amitriptyline and TRAIL and also presented a novel mechanism involved in DR4 and DR5 upregulation.
\end{abstract}

Correspondence to: Professor Sang-Youel Park, Biosafety Research Institute, College of Veterinary Medicine, Jeonbuk National University, Iksan, Jeonbuk 54596, Republic of Korea E-mail: sypark@chonbuk.ac.kr

Key words: amitriptyline, tumor necrosis factor-related apoptosisinducing ligand, death receptor-4/5, apoptosis, autophagy

\section{Introduction}

Lung cancer is the most common cause of cancer-related deaths worldwide (1). In a study in 2018 in the U.S., lung cancer was the second most common cancer diagnosis by sex and was newly diagnosed in $14 \%$ of men and $13 \%$ of women (2). Typically, patients with non-small cell lung cancer (NSCLC) are identified with advanced cancer and approximately $16.43 \%$ of patients survive for five years $(3,4)$. Lung cancer treatments include surgery, radiotherapy, and chemotherapeutic drugs and their combinations $(5,6)$. Specific combination strategies with potent chemotherapeutic drugs may be a potential approach to cancer treatment $(7,8)$.

Tumor necrosis factor-related apoptosis-inducing ligand (TRAIL) is a highly attractive anticancer treatment that selectively kills cancer cells without causing toxicity to normal cells (9). TRAIL binds to death receptor (DR)4/DR5 to initiate apoptotic cell death. Along with A549 lung cancer cells, a large number of cancer cells are resistant to TRAIL due to the insufficient expression of death receptors DR4/DR5 and the extreme expression of decoy receptors, as well as the mutation of TRAIL receptors (10-12). Interestingly, it is possible to overcome TRAIL resistance with suitable pharmacological agents that can enhance the expression of TRAIL receptors $(13,14)$.

Autophagy plays an important role in maintaining cellular homeostasis (15). Autophagy suppresses tumors by maintaining cellular homeostasis; however, these tumors can play a survival role when cancer has already developed (16). Tumor cells fulfill their energy demands by using autophagy and through this process develop treatment resistance (17). Numerous previous studies have demonstrated that blocking autophagy flux by inhibiting autophagosome-lysosome fusion can be an encouraging approach for cancer therapy $(18,19)$. Consequently, pharmacological agents that induce autophagosome accumulation by inhibiting lysosomal fusion and increase TRAIL receptors can be an effective approach to overcome TRAIL resistance.

Depression is a common psychological disorder in cancer patients. Continuous depression reduces the antitumor immune response and creates a favorable environment for tumor growth (20). Animal model studies have shown that behavioral stress induces the rapid development of prostate (20), ovarian (21), pancreatic (22), and breast cancer (22), as well 
as carcinomas and malignant melanomas (23). Several studies have recommended that amitriptyline is a productive option to control cancer-associated depression, anxiety, and pain $(24,25)$.

Amitriptyline is a psychoactive tricyclic antidepressant (TCA) drug. The drug has been revealed to markedly exert effective anticancer effects on a large number of cancer cell types, including colon, prostate, glioma osteosarcoma, skin, squamous carcinoma, and multiple myeloma (26). Another study revealed that amitriptyline induced p53 expression, activated caspase-3, and decreased anti-apoptotic proteins Bcl-2 and Mcl-1 in multiple myeloma. In combination with bortezomib, amitriptyline induced apoptosis in multiple myeloma (27). Amitriptyline has also been studied as a potential candidate for oxidative therapy for its cytotoxicity in $\mathrm{H} 460$ lung cancer cells, which may be more effective than other chemotherapeutic drugs (28).

In the present study, it was demonstrated that amitriptyline could sensitize TRAIL-resistant lung cancer cells to induce TRAIL-mediated apoptosis. The molecular mechanism underlying the anticancer effects of amitriptyline in combination with TRAIL and, specifically, the role of autophagy in lung cancer treatment was also investigated.

\section{Materials and methods}

Cells and culture systems. A549 lung cancer cells were acquired from the American Type Culture Collection (ATCC). The cells were cultured in Roswell Park Memorial Institute (RPMI)-1640 medium (Gibco BRL; Thermo Fisher Scientific, Inc.) supplemented with $10 \%(\mathrm{v} / \mathrm{v})$ fetal bovine serum (Sigma-Aldrich; Merck KGaA) and antibiotics $(100 \mu \mathrm{g} / \mathrm{ml}$ penicillin-streptomycin; Sigma-Aldrich; Merck KGaA) at $37^{\circ} \mathrm{C}$ in a $5 \% \mathrm{CO}_{2}$ incubator.

Reagents. Amitriptyline was purchased from Cayman Chemical Company, and chloroquine (CQ) $(20 \mu \mathrm{M})$ was obtained from Sigma-Aldrich; Merck KGaA. Human recombinant TRAIL (100 ng/ml) was purchased from AbFrontier.

Cell viability assay. Cell viability was assessed with MTT and crystal violet staining assays. The cells were plated in 12-well plates at a density of $1.0 \times 10^{4}$ cells/well and incubated at $37^{\circ} \mathrm{C}$ for $24 \mathrm{~h}$. The cells were pretreated with different concentrations of amitriptyline $(0,10,20$ and $40 \mu \mathrm{M})$ or CQ for $12 \mathrm{~h}$ and then exposed to recombinant TRAIL $(100 \mathrm{ng} / \mathrm{ml})$ for $3 \mathrm{~h}$. Cell morphology was observed under an inverted light microscope (magnification, x100; Nikon Corporation). Cell viability was assessed by adding $50 \mu \mathrm{l}$ of $5 \mathrm{mg} / \mathrm{ml}$ methyl-thiazolyl tetrazolium (MTT) to each well and incubating them at $37^{\circ} \mathrm{C}$ for $2 \mathrm{~h}$. After incubation, the MTT solution was removed and the cells were treated with $500 \mu \mathrm{l}$ of dimethyl sulfoxide and the absorbance was measured at $570 \mathrm{~nm}$ with a spectrophotometer (Bio-Rad Laboratories). For the crystal violet assay, the cells were stained with a staining solution $(0.5 \%$ crystal violet in $30 \%$ ethanol and 3\% formaldehyde) for 10-20 min at room temperature (RT), washed 3-4 times with phosphate-buffered saline (PBS), and then imaged.

Lactate dehydrogenase (LDH) assay. Cytotoxicity was analyzed in the collected supernatant and determined by an
LDH cytotoxicity detection kit (Takara Bio, Inc.) following the manufacturer's protocol. LDH activity was measured at $490 \mathrm{~nm}$ using a microplate reader (Spectra Max M2; Molecular Devices, LLC).

Colony-formation assay. Cells were plated in 6-well plates at $37^{\circ} \mathrm{C}$ and treated with the indicated doses of amitriptyline (40 $\mu \mathrm{M}), \mathrm{CQ}(20 \mu \mathrm{M})$ and TRAIL (100 $\mathrm{ng} / \mathrm{ml})$. Two days later, the culture medium was changed with new medium without amitriptyline, CQ and TRAIL, and the culture continued for 7 days. Colonies were fixed for $20 \mathrm{~min}$ at RT in $4 \%$ paraformaldehyde, stained with $0.05 \%(\mathrm{w} / \mathrm{v})$ crystal violet for $10 \mathrm{~min}$ at RT, and counted under an inverted light microscope (Nikon Corporation).

Flow cytometric analysis of apoptosis. Apoptosis was evaluated cells (50 cells/ $\mu \mathrm{l})$ using Annexin V-FITC Assay Kit (Santa Cruz Biotechnology, Inc.), for flow cytometry according to the manufacturer's instructions (Guava EasyCyte HT System; EMD Millipore). The fluorescence was measured at $488 \mathrm{~nm}$ of excitation and 525/30 emission using Guava ${ }^{\circledR}$ InCyte and GuavaSuite Software.

Western blot analysis. The cells were lysed in lysis buffer [25 mM HEPES (pH 7.4), $100 \mathrm{mM}$ ethylenediaminetetraacetic acid (EDTA), $5 \mathrm{mM} \mathrm{MgCl}_{2}, 0.1 \mathrm{mM}$ dithiothreitol (DTT), and a protease inhibitor cocktail], and sonicated to prepare cell lysates. Equal amounts $(40 \mu \mathrm{g})$ of proteins were separated by $8-15 \%$ sodium dodecyl sulfate-polyacrylamide gel electrophoresis (SDS) and transferred onto polyvinylidene fluoride (PVDF) membranes. The membranes were blocked at $25^{\circ} \mathrm{C}$ for $1 \mathrm{~h}$, and then incubated with the indicated concentrations of primary antibodies at $25^{\circ} \mathrm{C}$ for $1 \mathrm{~h}$, and then they were blotted with anti-mouse IgG (Alexa Fluor 647 conjugate) secondary antibodies (product. no. 4410; 1:2,000; Cell Signaling Technology, Inc.) at $25^{\circ} \mathrm{C}$ for $1 \mathrm{~h}$. The membranes were developed with enhanced chemiluminescence reagents (ECL; GE Healthcare Life Sciences). Primary antibodies used for the immunoblotting included: DR4 (product. code. ab8414; 1:1,000), DR5 (product. code. ab181846; 1:10,000) (both from Abcam), LC3 (product. no. 3868; 1:1,000), p62 (cat. no. 5114; 1:1,000), cleaved caspase-3 (product. no. 9661; 1:500), p-AMPK $\alpha$ (product. no. 2531; 1:1,000) all from Cell Signaling Technology, Inc., cleaved caspase- 8 (cat. no. 551242; 1:1,000, BD Pharmingen; BD Biosciences), and $\beta$-actin (cat. no. A2228; 1:2,000, Sigma-Aldrich; Merck $\mathrm{KGaA}$ ). The bands were visualized and captured with a Fusion-FX7 using easy-to-use FusionCapt V16.07 Software (both Vilber Lourmat).

Immunocytochemistry. The cells $\left(\sim 1 \times 10^{6}\right.$ cells) were grown on glass coverslips, then treated with amitriptyline, washed with $1 \%$ PBS, and fixed with $4 \%$ paraformaldehyde in PBS at RT for $15 \mathrm{~min}$. They were then washed twice with ice-cold PBS and incubated at RT for $10 \mathrm{~min}$ in PBS containing $0.25 \%$ Triton X-100. After the incubation, the cells were washed three times with PBS and blocked with $1 \%$ BSA in PBST for $30 \mathrm{~min}$. The cells were then incubated with a primary antibody [anti-p62 (1:1,000; product. no. 5114; Cell Signaling Technology, Inc.) and DR4/5 diluted with $1 \%$ BSA 
in PBST] in a $5 \% \mathrm{CO}_{2}$ incubator for $3 \mathrm{~h}$ at $37^{\circ} \mathrm{C}$. After incubation, the cells were washed three times with PBS. Next, the cells were incubated with a secondary antibody [(Alexa Fluor $^{\circledR}$ 488-conjugate; donkey polyclonal anti-rabbit, 1:500; cat. no. A-21206; Thermo Fisher Scientific, Inc.), diluted with $1 \% \mathrm{BSA}$ in PBST] in the dark for $2 \mathrm{~h}$ at RT. The solution was removed and the cells were washed 3-4 times with PBS. The cells were treated with DAPI (4',6-diamidino-2-phenylindole, D9564; Sigma-Aldrich;Merck KGaA) and incubated for $10 \mathrm{~min}$ at $25^{\circ} \mathrm{C}$. The cells were washed three times, then mounted with fluorescent mounting medium and the images were captured using a fluorescence microscope (Nikon ECLIPSE 80i; magnification, x400; Nikon Corporation).

Transmission electron microscopy. Trypsinized cells were fixed with $2 \%$ glutaraldehyde (Electron Microscopy Sciences) for $2 \mathrm{~h}$ at $4^{\circ} \mathrm{C}$ in PBS, followed by $2 \%$ osmium tetroxide (Electron Microscopy Sciences), and dehydrated with an ethanol series $(25,50,70,90$ and $100 \%)$ for 5 min each. After dehydration, the samples were embedded in epoxy resin (Embed 812; Electron Microscopy Sciences) for $48 \mathrm{~h}$ at $60^{\circ} \mathrm{C}$ according to the manufacturer's instructions. Ultrathin sections $(60 \mathrm{~nm})$ were prepared using an LKB III ultratome (Leica Microsystems $\mathrm{GmbH}$ ) and stained with $0.5 \%$ uranyl acetate (Electron Microscopy Sciences) for $20 \mathrm{~min}$ and $0.1 \%$ lead citrate (Electron Microscopy Sciences) for $7 \mathrm{~min}$ at RT. Images were captured on a Hitachi $\mathrm{H} 7650$ electron microscope (magnification x10,000; Hitachi, Ltd.) installed at the Center for University-Wide Research Facilities (CURF) at Jeonbuk National University (JBNU).

RNA interference. The cell line was transfected with small interfering (si)RNA using Lipofectamine (Invitrogen; Thermo Fisher Scientific, Inc.) according to the manufacturer's protocol. Knockdown proficiency was assessed by immunoblotting and cell viability tests. DR4 and DR5 siRNA were purchased from Qiagen China Co., Ltd., each with mixed two target sequences (forward, 5'-TAGCTCAGC TGCAACCATCAA-3' and reverse, 5'-CAGGCAATCGAC ATAATATAT-3' for DR4; forward, 5'-ACCAGGTGTGAT TCAGGTGAA-3' and reverse, 5'-CCGACTTCACTTGAT ACTATA-3' for DR5). The synthetic siRNA and scramble siRNA [negative control (NC)] (Qiagen) were transfected using HiPerfect transfection reagent (Qiagen), according to the manufacturer's protocol. Briefly, each sequence of siRNA $(20 \mu \mathrm{mol} / \mathrm{ml})$ and $10 \mu \mathrm{l}$ Lipofectamine 2000 was diluted in serum-free medium $(250 \mu \mathrm{l})$ at RT for $5 \mathrm{~min}$, mixed together, and incubated for $30 \mathrm{~min}$ at RT. The cells were incubated with siRNA or NC siRNA for $6 \mathrm{~h}$ and the medium was then changed with $10 \%$ FBS for $24 \mathrm{~h}$, followed by subsequent experimentation.

Reverse transcription-quantitative polymerase chain reaction $(R T-q P C R)$. The DR4 and DR5 mRNA transcripts were measured using quantitative SYBR Green-based real-time qPCR. Total RNA was extracted from the A549 cells with RiboEX (GeneAll Biotechnology). The total RNA extracts were then converted into cDNA by using reverse transcriptase (TOPscript $^{\mathrm{TM}}$ One-step RT PCR kit; Enzynomics Co., Ltd.) using a CFX96 ${ }^{\mathrm{TM}}$ Real-PCR Detection system (Bio-Rad
Laboratories, Inc.), following the manufacturer's instructions at $85^{\circ} \mathrm{C}$ for $5 \mathrm{sec}, 37^{\circ} \mathrm{C}$ for $10 \mathrm{~min}$ and $4^{\circ} \mathrm{C}$ for $15 \mathrm{~min}$. Gene primers $(1 \mu \mathrm{l})$ and SYBR-Green (Bio-Rad Laboratories, Inc.) contained in a total reaction volume of $20 \mu \mathrm{l}$ were used to conduct the RT-qPCR . The reaction protocols were as follows: Predenaturation at $95^{\circ} \mathrm{C}$ for $30 \mathrm{sec}, 40$ cycles of denaturation at $95^{\circ} \mathrm{C}$ for $5 \mathrm{sec}$ and annealing at $60^{\circ} \mathrm{C}$ for $30 \mathrm{sec}$. GAPDH were used as the respective internal control. The sequences of the primers used were: DR4 forward, 5'-GGGACAGCA CGGACCCAGTG-3' and reverse, 5'-ATCCTTGACCTTGAC CATCC-3'; DR5 forward, 5'-GCGGTCCTGCTGTTGGTC TC-3' and reverse, 5-GCTTCTGTCCACACGCTCAG-3'; and GAPDH as an internal control forward, 5'-TGCACCACC AACTGCTTAG-3' and reverse, 5'-GGATGCAGGGATGAT GTT-3'. All data were evaluated using Bio-Rad CFX manager, version 2.1 analysis software (Bio-Rad Laboratories, Inc.). The collected data from three independent experiments were analyzed using the $2^{-\Delta \Delta \mathrm{Cq}}$ method (29).

Statistical analysis. The data are expressed as the mean \pm standard deviation (SD) from three independent experiments. The significance of the differences between the treatments was analyzed using one-way analysis of variance (ANOVA), followed by the Tukey-Kramer post hoc test. Statistical analyses were executed using GraphPad Prism 7 (GraphPad Software, Inc). $\mathrm{P}<0.05$ was considered to indicate a statistically significant difference.

\section{Results}

Amitriptyline enhances TRAIL-induced apoptosis in lung cancer cells. To explore the synergistic effect of amitriptyline with TRAIL on the inhibition of lung cancer cell viability, the A549 lung adenocarcinoma cell line was selected. The results revealed a strong synergistic effect on this cell line. The cells were pretreated with $40 \mu \mathrm{M}$ amitriptyline for $12 \mathrm{~h}$, followed by co-treatment with $100 \mathrm{ng} / \mathrm{ml}$ of TRAIL for $3 \mathrm{~h}$. The cell morphologies were examined under a light microscope. Co-treatment with TRAIL increased the number of cells undergoing apoptotic death (Fig. 1A). The MTT assay revealed that the combined treatment triggered significant growth inhibition in a dose-dependent manner (Fig. 1B). The LDH levels after combined treatment demonstrated that amitriptyline induced apoptosis in a dose-dependent manner; however, the individual use of amitriptyline or TRAIL alone failed to show similar effects (Fig. 1C). Additionally, the colony-forming capacity of A549 cancer cells after combination treatment of amitriptyline and TRAIL was examined. Amitriptyline alone treatment not shown any inhibition effects (data now shown), but combine treatment with TRAIL gradually reduced the colony formation in a dose-dependent manner (Fig. 1D). These results indicated that amitriptyline significantly sensitized TRAIL-resistant A549 lung adenocarcinoma cells to TRAIL-mediated apoptosis.

$D R 4$ and DR5 enhancement is required by amitriptyline for TRAIL-mediated apoptosis. To evaluate the principal mechanism underlying the apoptosis of A549 cells prompted by the combination of amitriptyline and TRAIL, the augmented expression of DRs associated with TRAIL-induced apoptosis 
A

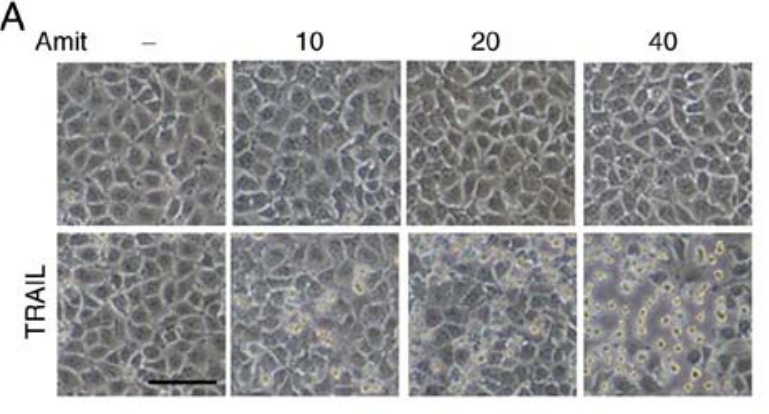

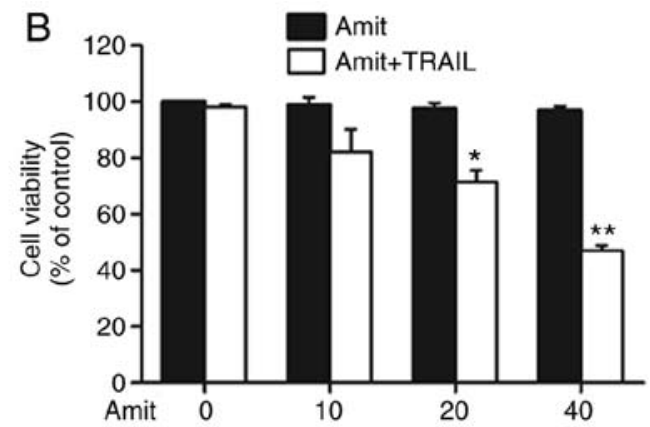

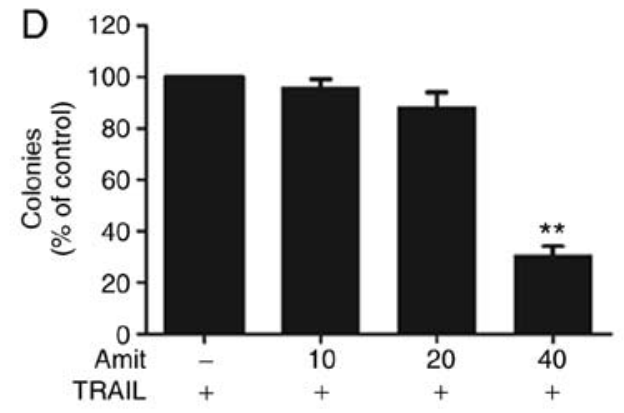

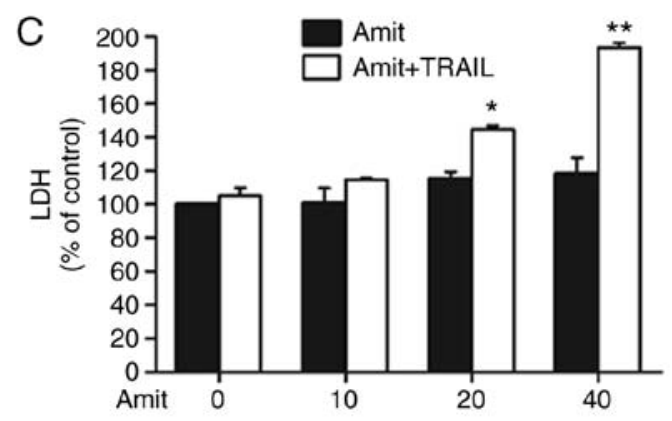

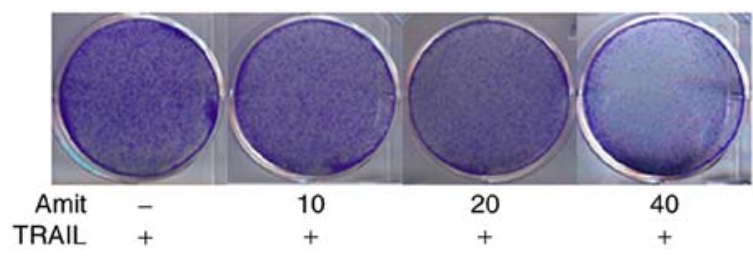

Figure 1. Amitriptyline enhances TRAIL-induced apoptosis in lung cancer cells. A549 cells were preincubated with the designated concentrations of amitriptyline for $12 \mathrm{~h}$ and then co-treated with $100 \mathrm{ng} / \mathrm{ml}$ of TRAIL for $3 \mathrm{~h}$. (A) Cell morphologies were captured and examined under a light microscope (magnification x100; scale bar, $50 \mu \mathrm{m}$ ). (B) MTT assays were used to reveal cell viability (bar graph). (C) Cytotoxicity was measured by LDH released from co-treatment. (D) Colonies were fixed with paraformaldehyde and stained with crystal violet dye and the number of colonies were counted under a light microscope. Statistically significant differences between the control and each indicated treatment group are presented as * $\mathrm{P}<0.01$ and ${ }^{* *} \mathrm{P}<0.001$. Amit, amitriptyline; TRAIL, tumor necrosis factor-related apoptosis-inducing ligand.

was explored. An important reason for TRAIL resistance in numerous cancer cell lines is associated with the decreased expression of TRAIL receptors DR4 and DR5 or upregulation of the decoy receptors DcR1 and DcR2 (30). Western blot analysis demonstrated that amitriptyline increased DR4 and DR5 expression levels in a dose-dependent manner and time-dependent manner (Fig. 2A). When assessed via mRNA expression, amitriptyline treatment increased the transcription of DR5, but not DR4, (Fig. 2B). These results indicated that amitriptyline may increase DR5 expression through transcriptional or post-transcriptional regulation and concurrently amitriptyline stabilized DR4 protein expression by inhibiting its degradation through post-translational regulation. Moreover, immunocytochemistry results demonstrated the significant expression of DR4 and DR5 in amitriptyline-treated cells compared to non-treated cells (Fig. 2C). The apoptosis-indicating proteins cleaved caspase- 8 and cleaved caspase- 3 were activated after treatment with amitriptyline and TRAIL compared to treatments with each individually (Fig. 2D). Furthermore, the apoptosis percentage by Annexin V assay was measured, which indicated that amitriptyline and TRAIL in combination enhanced apoptotic cell death (Fig. 2E and F). Collectively, these findings indicated that DR4 and DR5 upregulated by amitriptyline induced TRAIL-mediated apoptosis in TRAIL-resistant A549 lung cancer cells.
Silencing of DR4 and DR5 expression negatively controls amitriptyline-induced TRAIL-mediated apoptosis. It was hypothesized that DR4 and DR5 played important roles in amitriptyline-induced TRAIL-mediated apoptosis. In support of this hypothesis, DR4 and DR5-specific siRNA were applied to silence DR4 and DR5 expression, respectively. The silencing of DR4 and DR5 expression with specific siRNA restored cell viability. These data provided evidence that DR4 and DR5 play an important role in enhancing the effect of amitriptyline on TRAIL-induced apoptosis. Cells were transfected with DR4 and DR5-specific siRNAs or a NC siRNA for $24 \mathrm{~h}$ and the cells were treated with amitriptyline for $12 \mathrm{~h}$, followed by incubation with TRAIL for an additional $3 \mathrm{~h}$ to assess cell viability or for $2 \mathrm{~h}$ for western blot analysis. The cell death induction capacity of amitriptyline combined with TRAIL significantly decreased after siRNA transfection. The combined effect of amitriptyline and TRAIL, however, on viability was similar in the NC siRNA-transfected cells (Figs. 3A and B, and 4A and B). Moreover, the colony formation-inhibiting capacity of amitriptyline combined with TRAIL-treated cells considerably decreased after siRNA transfection. The colony formation-inhibiting capacity of amitriptyline combined with TRAIL was similar in the NC control siRNA-transfected cells (Figs. 3C and 4C). Western blot analysis revealed that the expression of DR4 and DR5 

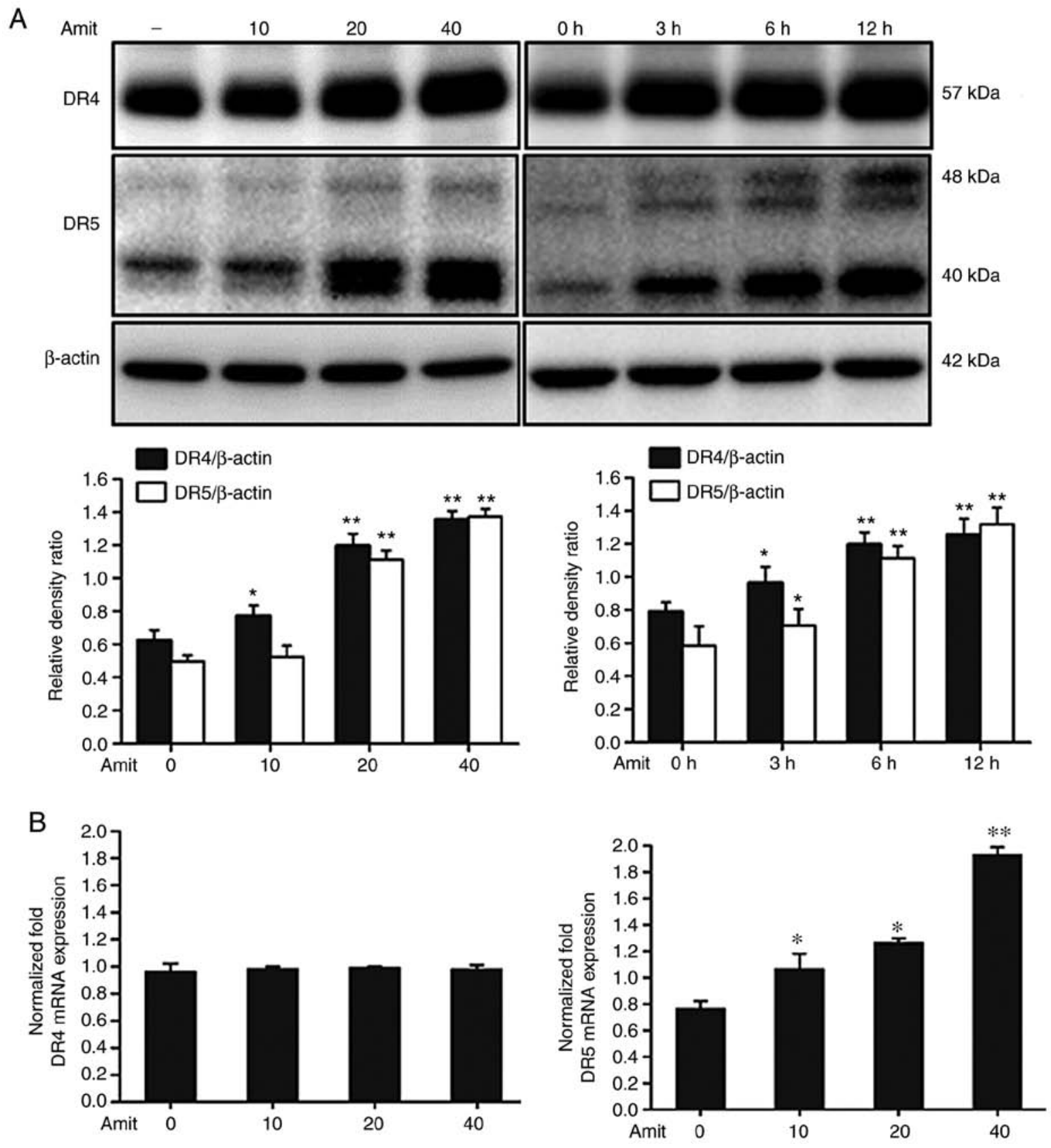

Figure 2. Continued.

was blocked after siRNA transfection compared to the non-transfected cells (Figs. 3D and 4D). These experimental findings confirmed that the upregulation of DR4 and DR5 is required in attenuating TRAIL resistance.

Amitriptyline blocks autophagy by inhibiting autophagosomelysosome fusion. To investigate the role of amitriptyline in autophagy flux, the well-known autophagy markers LC3-II and p62 were analyzed. Western blot analysis revealed the conversion of LC3I to LC3-II, indicating the formation of complete autophagosomes. However, p62 is a cargo adaptor protein that depends on lysosomes or proteasomes for degradation (31). The expression of LC3-II and p62 was increased following amitriptyline treatment, indicating the blocking of autophagy flux by inhibiting autophagosome-lysosome fusion in the late stage of autophagy (Fig. 5A). The immunocytochemistry images also demonstrated the increased expression of p62 in a dose-dependent manner (Fig. 5B). Transmission electron microscopy revealed the higher accumulation of autophagic vacuoles compared to the control, confirming autophagy flux inhibition by amitriptyline (Fig. 5C). These results indicated that amitriptyline blocked autophagy flux at the final stage of autophagy.

Blocking autophagy induces DR4 and DR5 upregulation and enhances TRAIL-mediated apoptosis. The role of autophagy blocking in death receptor expression was investigated using an autophagy inhibitor. Blocking autophagy flux with a final stage autophagy inhibitor CQ upregulated both DR4 and DR5 expression, leading to an increase in apoptosis. The cells were treated with or without $20 \mu \mathrm{M} C Q$ and the indicated doses of amitriptyline for $12 \mathrm{~h}$. Western blot analysis revealed that 


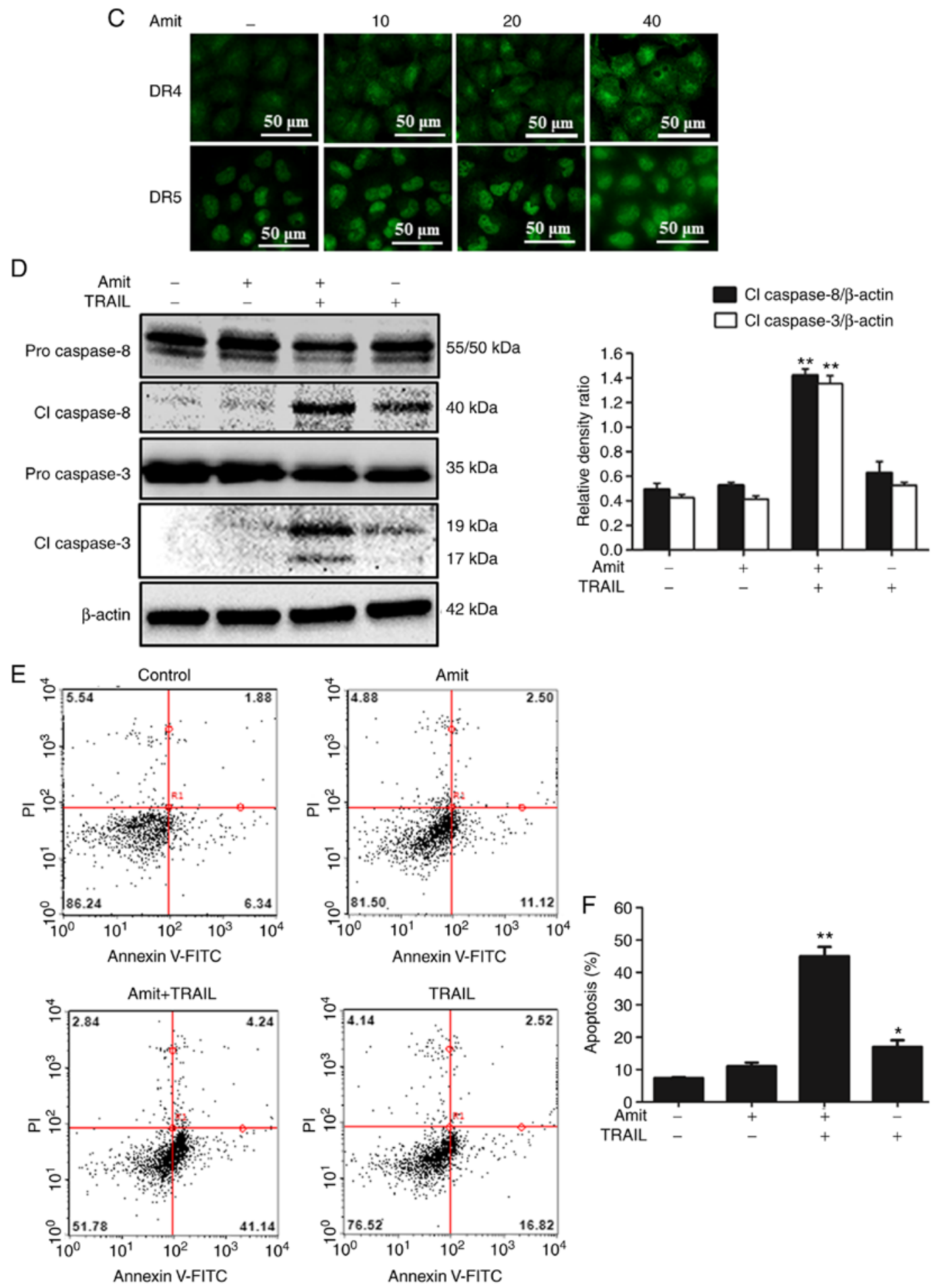

Figure 2. DR4 and DR5 enhancement are required by amitriptyline for TRAIL-mediated apoptosis. A549 cells were preincubated with the designated doses of amitriptyline for $12 \mathrm{~h}$. (A) Harvested cell lysates were collected and subjected to western blotting to determine the dose- and time-dependent expression of DR4 and DR5. (B) DR4 and DR5 mRNA expression assessed by reverse transcription-quantitative polymerase chain reaction. GAPDH was used as an internal control to indicate equivalent RNA loading. (C) The immunocytochemistry results revealed the significant expression of DR4 and DR5 in dose-dependent manners (scale bar, $50 \mu \mathrm{m})$. (D) Amitriptyline $(40 \mu \mathrm{M})$-treated cells were incubated for $12 \mathrm{~h}$ and additionally exposed to $100 \mathrm{ng} / \mathrm{ml} \mathrm{TRAIL} \mathrm{protein} \mathrm{for} 3 \mathrm{~h}$ Intracellular apoptosis regulatory proteins cleaved caspase- 8 and cleaved caspase- 3 were analyzed by western blotting. $\beta$-actin was detected as a protein loading control. (E) Cells were treated with Annexin V-FITC and PI, which binds to phosphatidylserine to the plasma membrane and nuclei during apoptosis. (F) Bar graph showing the averages of the Annexin V-positive cells. Values represent the mean $\pm \mathrm{SD}(\mathrm{n}=3)$. Statistically significant differences between the control and each indicated treatment group are presented as ${ }^{*} \mathrm{P}<0.01$ and ${ }^{* *} \mathrm{P}<0.001$. TRAIL, tumor necrosis factor-related apoptosis-inducing ligand; DR, death receptor; Amit, amitriptyline.

amitriptyline and CQ increased the levels of LC3-II. Moreover, amitriptyline alone increased p62 levels in a dose-dependent manner. These results revealed that amitriptyline blocked autophagy flux to induce apoptosis (Fig. 6A). Furthermore, amitriptyline and the autophagy inhibitor CQ increased DR4 and DR5 expression (Fig. 6B). After $12 \mathrm{~h}$ treatment with CQ 

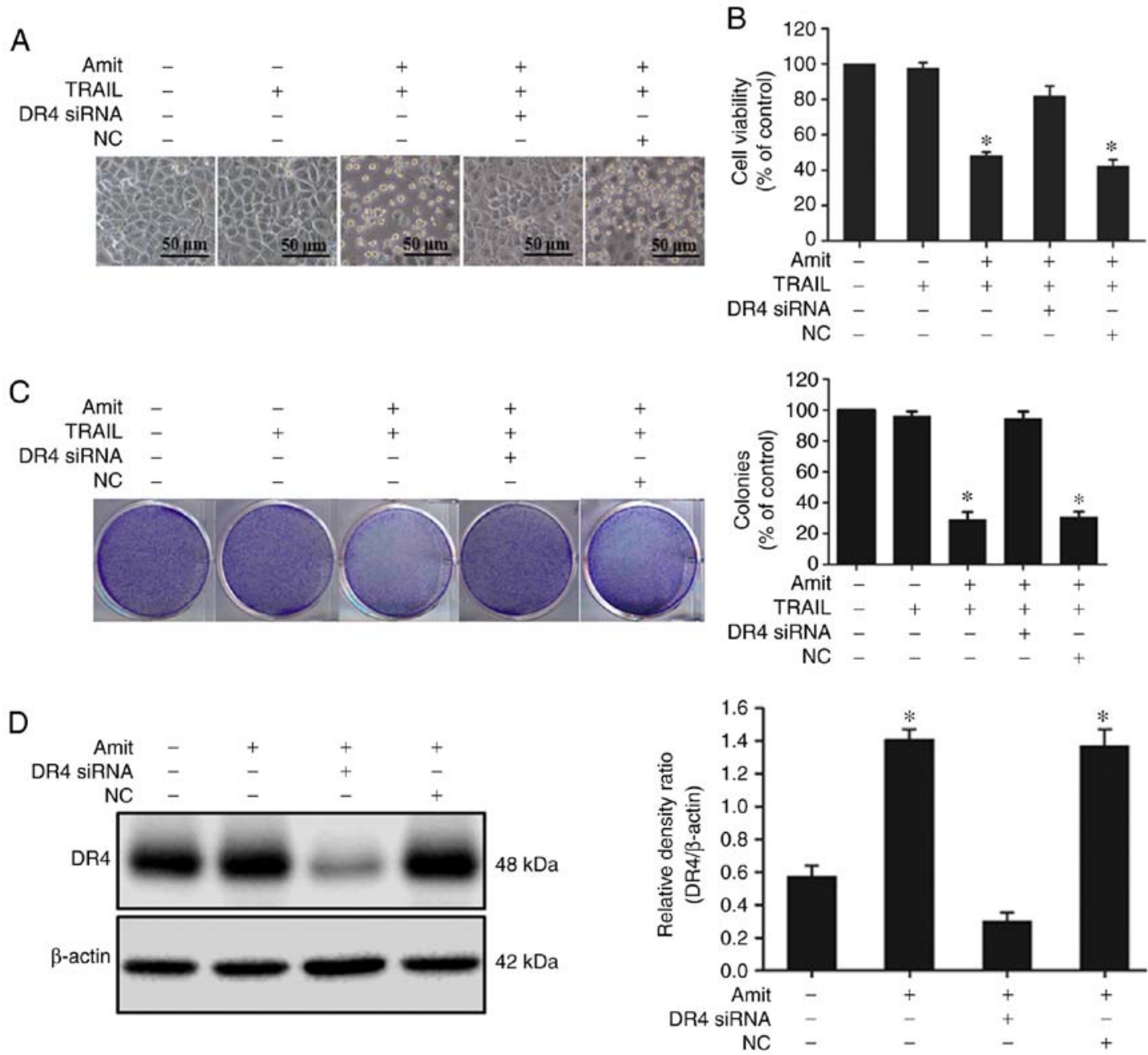

Figure 3. Silencing of DR4 expression negatively controls amitriptyline-induced TRAIL-mediated apoptosis. DR4 siRNA and control siRNA (40 nM) were transfected for $24 \mathrm{~h}$, then the cells were treated with amitriptyline $(40 \mu \mathrm{M})$ for $12 \mathrm{~h}$ and finally, $100 \mathrm{ng} / \mathrm{ml}$ of TRAIL protein was added for $3 \mathrm{~h}$. (A) Images of the cells were captured and morphological variations were examined under a light microscope (magnification, x100; scale bar, $50 \mu \mathrm{m}$ ). (B) MTT assays were performed to reveal cell viability percentages (bar graph). (C) Cell colonies were stained with crystal violet dye and the number of colonies were counted. Statistically significant differences between the control and each indicated treatment group are presented as * $\mathrm{P}<0.001$. (D) Whole-cells lysates were prepared and analyzed by western blotting to determine the expression of DR4. TRAIL, tumor necrosis factor-related apoptosis-inducing ligand; DR, death receptor; siRNA, small interfering RNA; NC, negative control; Amit, amitriptyline.

and amitriptyline, along with an additional $2 \mathrm{~h}$ TRAIL treatment, the expression of apoptosis-associated proteins cleaved caspase- 8 and cleaved caspase- 3 were observed. Cell lysates analyzed by western blotting demonstrated that treatment with CQ and TRAIL also activated caspase-8 and caspase-3 (Fig. 6C). The immunocytochemistry results also revealed that the CQ and TRAIL co-treatment expressed cleaved caspase-8 and cleaved caspase-3 compared to treatment with CQ or TRAIL alone (Fig. 6D). Additionally, to investigate the role of autophagy in TRAIL-mediated cell death, the cells were preincubated with CQ or amitriptyline with the indicated doses for $12 \mathrm{~h}$, and then additionally incubated with TRAIL for $3 \mathrm{~h}$. The cell morphology analyzed by light microscopy demonstrated slight cell death of the A549 cells treated with either TRAIL or amitriptyline alone. TRAIL-mediated cell death, however, was strongly increased by the combination of amitriptyline or CQ with TRAIL (Fig. 7A). In addition, A549 cells treated with either TRAIL, amitriptyline or CQ alone slightly reduced colony formation capacity; but, TRAIL in combination with amitriptyline or CQ strongly inhibited the colony formation capacity of A549 cells (Fig. 7B). The MTT assay showed reduced viability and significantly increased cell death in cells treated with amitriptyline or CQ plus TRAIL (Fig. 7C). The LDH assay also showed that CQ or amitriptyline combined with TRAIL increased apoptotic cell death (Fig. 7D). Overall, these results indicated that blocking autophagy-induced DR4 and DR5 upregulation aggravated TRAIL-mediated apoptosis.

\section{Discussion}

TRAIL, a member of the tumor necrosis factor (TNF) ligand superfamily with the exclusive ability to induce cell-specific apoptosis with negligible or no toxicity to normal cells, represents a promising approach to treating cancer cells (32-34). TRAIL binds to DR4 (TRAIL-R1) and DR5 (TRAIL-R1), to form a death-inducing signaling complex (DISC), which is associated with the adaptor molecule Fas-associated protein with death domain (FADD), and then recruits pro-caspase- 8 and forms a DISC. The recruitment of pro-caspase- 8 causes the 
A

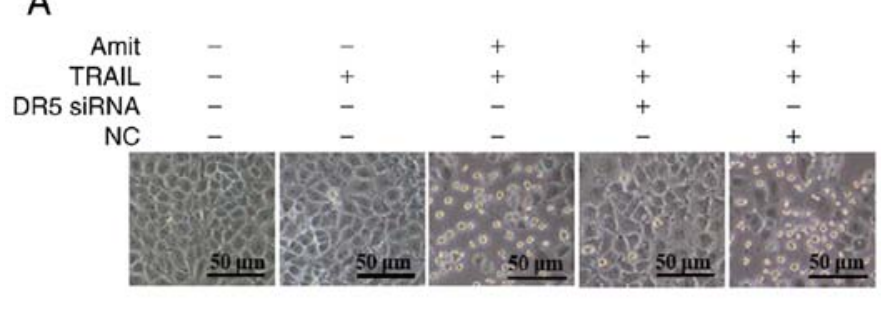

C

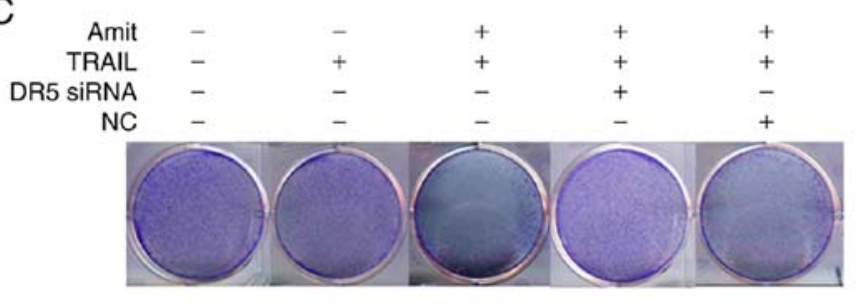

D

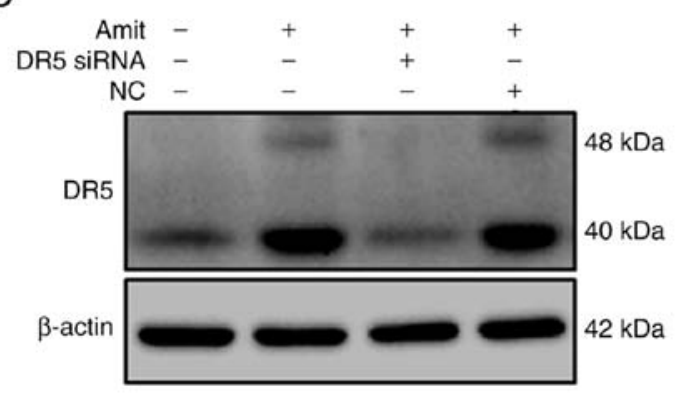

B
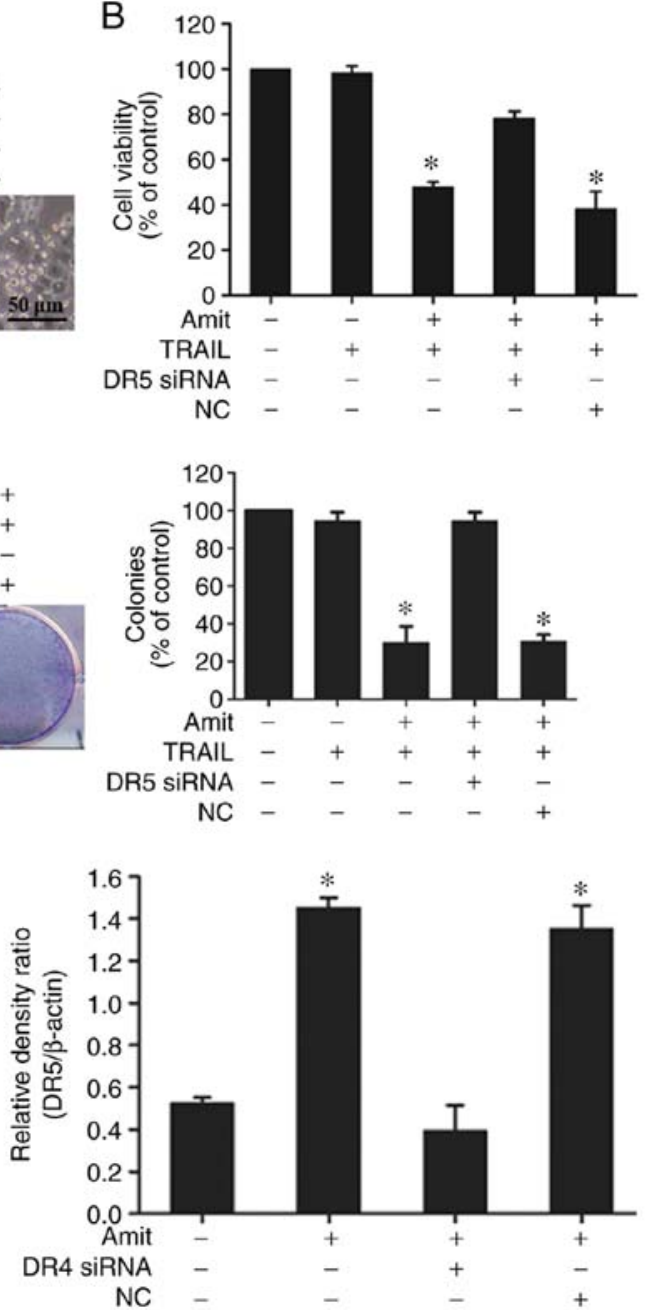

Figure 4. Silencing of DR5 expression negatively controls amitriptyline-induced TRAIL-mediated apoptosis. DR5 siRNA and control siRNA (40 nM) were transfected for $24 \mathrm{~h}$, then the cells were treated with amitriptyline (40 $\mu \mathrm{M}$ ) for $12 \mathrm{~h}$ and finally, $100 \mathrm{ng} / \mathrm{ml}$ of TRAIL protein was added for $3 \mathrm{~h}$. (A) Images of the cells were captured and morphological variations were examined under a light microscope (magnification, x100; scale bar, $50 \mu \mathrm{m}$ ). (B) Cell colonies were stained with crystal violet dye and the number of colonies were counted. (C) MTT assays were performed to reveal the cell viability percentages (bar graph). Statistically significant differences between the control and each indicated treatment group are presented as * $\mathrm{P}<0.001$. (D) Whole-cell lysates were prepared and analyzed by western blotting to determine the expression of DR5. TRAIL, tumor necrosis factor-related apoptosis-inducing ligand; DR, death receptor; siRNA, small interfering RNA; NC, negative control; Amit, amitriptyline.

activation of DISC and then the consequent cleavage of required caspases-8/9/7/6. Following this, caspase-3 induces apoptotic cell death (35-38). The involvement of DRs in TRAIL-mediated apoptosis enhanced both the intrinsic and extrinsic apoptosis pathways (39). TRAIL agonists against TRAIL receptors are actively being developed for cancer treatment due to their safety and high specificity compared to other TNF family members $(40,41)$. The development of resistance toward TRAIL and TRAIL-R agonists, however, may limit their effectiveness for monotherapy treatment. Thus, agents that can increase TRAIL-induced apoptosis and sensitize TRAIL-resistant cancer cells to TRAIL are necessary to overcome resistance $(42,43)$.

Autophagy involves an alternative cell-death mechanism, termed programmed cell death type II (44). The main functional role of autophagy in cells is to eliminate damaged cytosolic organelles and proteins. In this process, cytosolic components are sequestered into double-membraned organelles, termed autophagosomes, which subsequently fuse with lysosomes to form autolysosomes that degrade internal substances $(45,46)$. A large body of evidence has demonstrated that autophagy can also play a cell survival role that delivers energy during metabolic stress and avoids cancer cell death by several anticancer agents $(47,48)$. Autophagy inhibition prompts cancer cell death, while autophagy shows a cell-protective role in anticancer treatments $(49,50)$. Autophagosome formation is designated by a lipid-conjugated form of LC3 that is commonly known as an autophagosome marker. The autophagosome merges with the lysosome where sequestosome-1 (commonly known as p62) incorporates into autophagosomes and degrades LC3II, along with additional cargo proteins (51). Blocking lysosomal degradation with a specific lysosomal inhibitor results in the prompt accumulation of p62, indicating the inhibition of autophagy flux (52). Clinically available autophagy inhibitors CQ or the related hydroxychloroquine (HCQ) act by inhibiting lysosomal fusion with autophagosomes. These drugs prevent cargo degradation by inhibiting the acidification of the lysosome, subsequently inhibiting the fusion of autophagosomes with lysosomes (53). Several studies have suggested that inhibiting autophagy-sensitized cancer cells and promoting apoptosis is a suitable target for cancer treatment $(54,55)$. The activation of autophagosome accumulation 

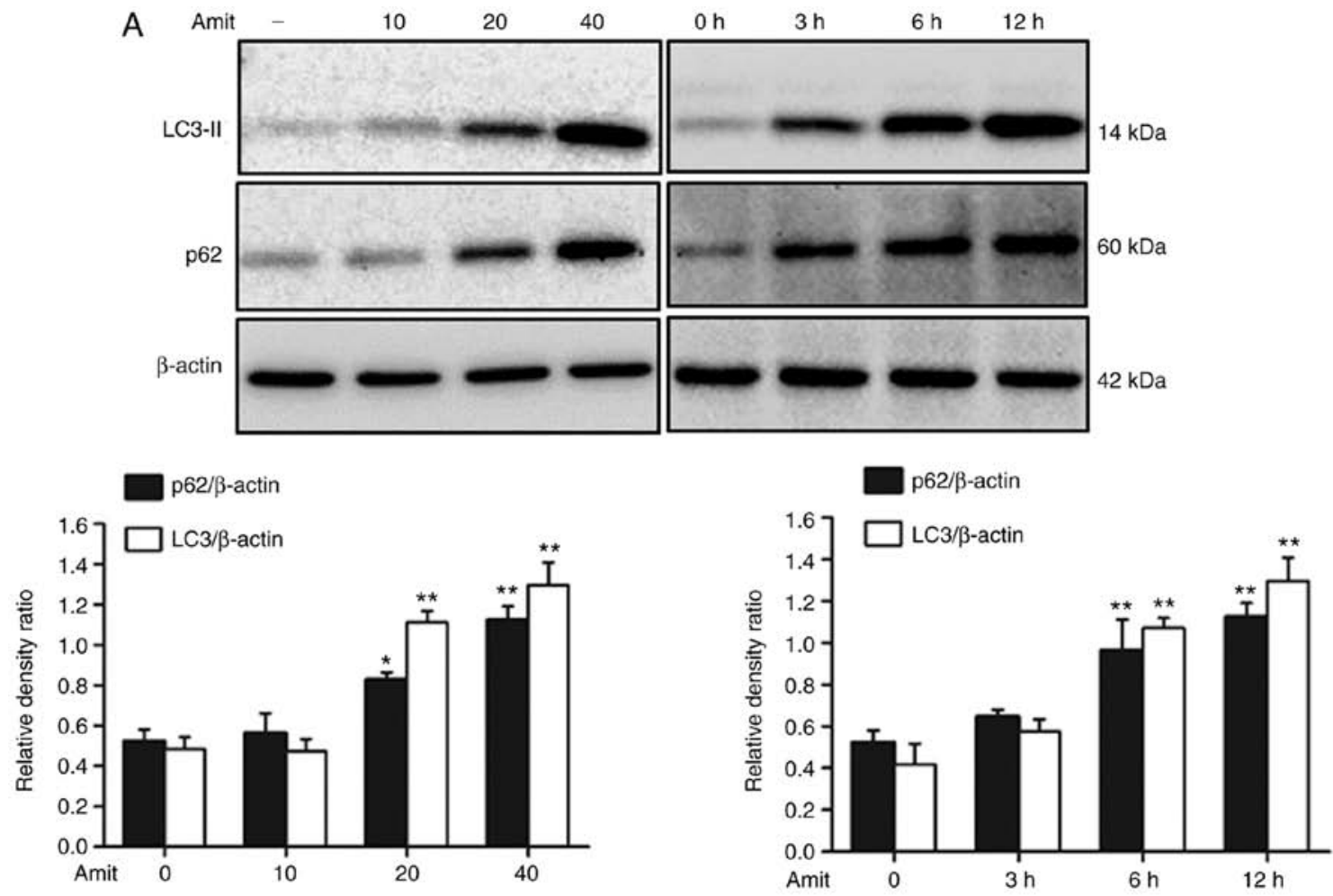

B
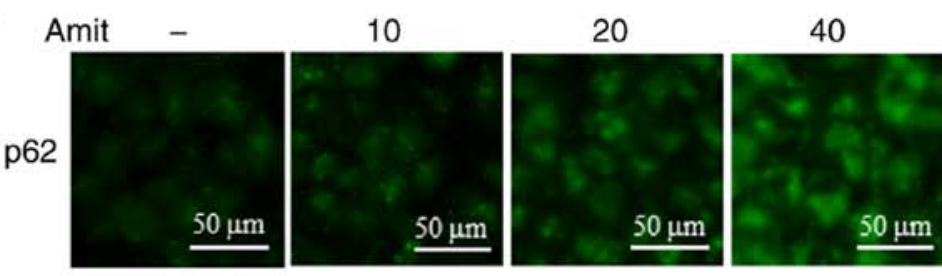

C Amit

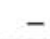

40
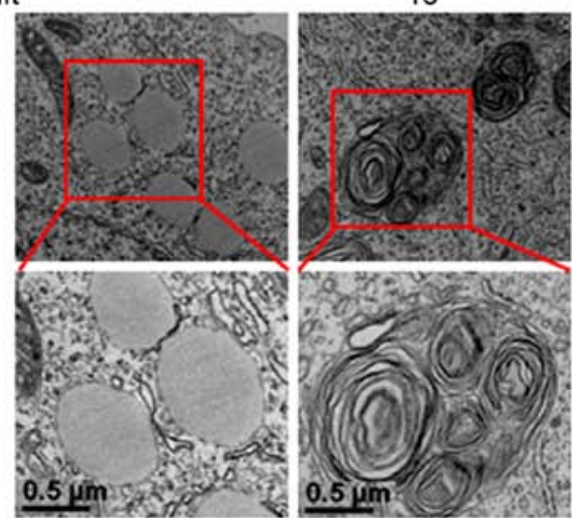

Figure 5. Amitriptyline blocks autophagy by inhibiting autophagosome-lysosome fusion. A549 cells were incubated with designated doses of amitriptyline for $12 \mathrm{~h}$ or $40 \mu \mathrm{M}$ amitriptyline for the indicated time-points. Whole-cell lysates were collected and analyzed by western blotting to determine (A) LC3 conversion, and p62 expression assessed at dose- and time-dependent manner. (B) The immunocytochemistry results displayed the significant upregulation of p62 expression in a dose-dependent fashion (scale bar, $50 \mu \mathrm{m}$ ). (C) The transmission electron microscopy results indicated the compact gathering of autophagosomes (scale bar, $0.5 \mu \mathrm{m}$ ). Statistically significant differences between the control and each indicated treatment group are presented as * $\mathrm{P}<0.01$ and ${ }^{* *} \mathrm{P}<0.001$. TRAIL, tumor necrosis factor-related apoptosis-inducing ligand; Amit, amitriptyline.

and inhibition of its degradation by lysosomes increase the death of cervical cancer cells and overcomes the resistance of chemotherapeutic drugs cisplatin and paclitaxel (56). Previous studies have demonstrated that inhibition of autophagy by impeding the acidification of the lysosome could be a possible way to restore DR5 expression and, in turn, augment the TRAIL-induced apoptosis $(57,58)$. Shin et al reported that the hepatitis B virus (HBV) X protein $(\mathrm{HBx})$ inhibited TRAIL signaling via autophagic removal of DR5 (59). Another recent study exposed the cause of TRAIL resistance in circulating tumor cells where DR5 is accumulated in autophagosomes for lysosomal degradation (60). Thus, DR5 has been determined to be controlled by the autophagy-lysosome pathway and inhibiting autophagy may be an effective option to overcome TRAIL resistance in cancer therapy. 
A

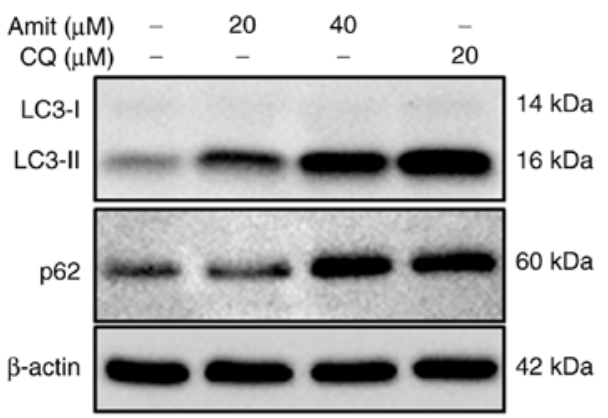

B

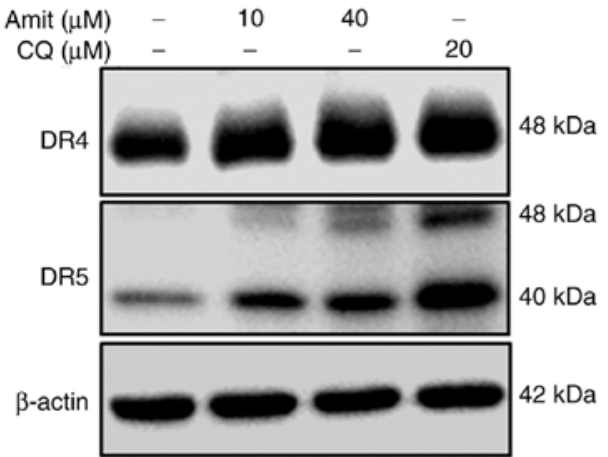

C

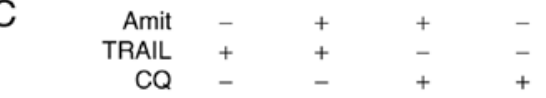

Pro caspase-

Cl caspase-

Pro caspase-3

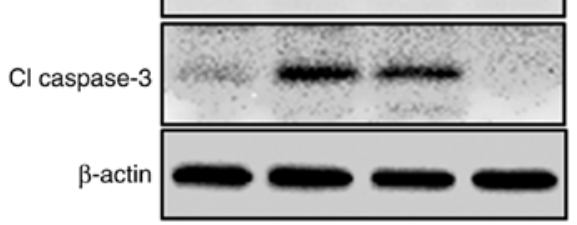

p62/3-actin

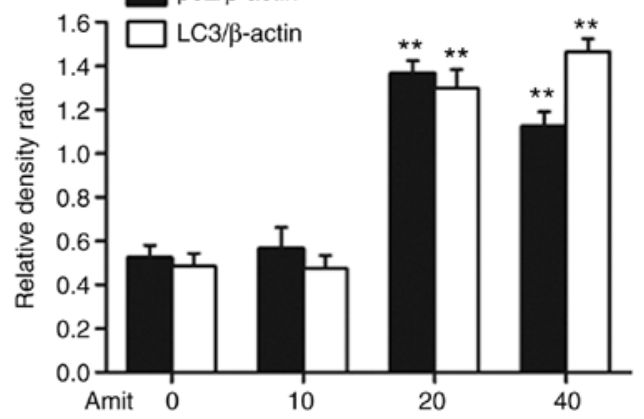

DR4/ $\beta$-actin
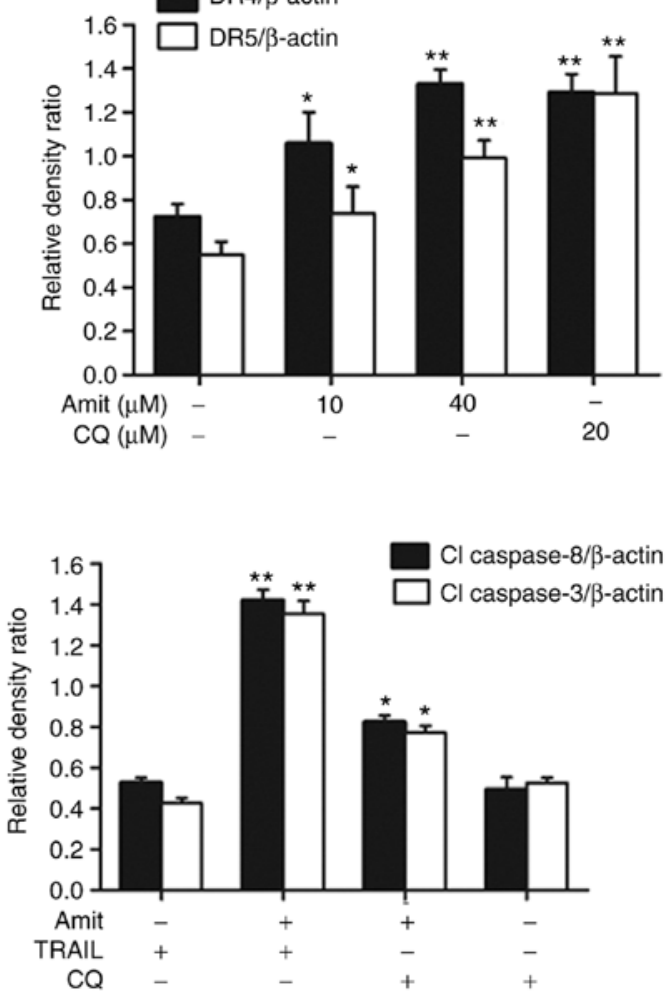
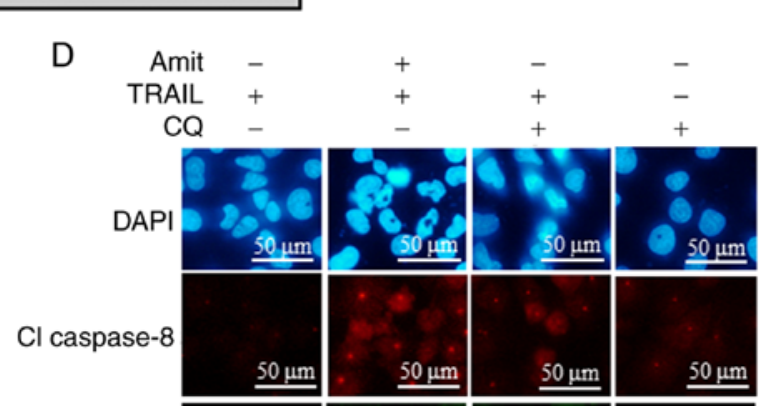

Cl caspase-3

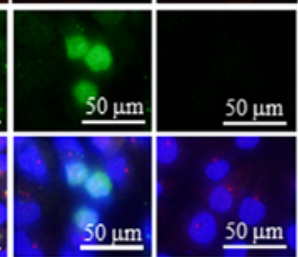

Figure 6. Blocking autophagy induces DR4/5 upregulation and enhances TRAIL-mediated apoptosis. The cells were incubated with or without CQ (20 $\mu \mathrm{M})$ and amitriptyline $(40 \mu \mathrm{M})$ for $12 \mathrm{~h}$. (A) LC3 and p62 were evaluated by western blotting. (B) DR4 and DR5 were evaluated by immunoblotting. (C) The cells were incubated with or without CQ $(20 \mu \mathrm{M})$ and amitriptyline $(40 \mu \mathrm{M})$ for $12 \mathrm{~h}$ and finally, with or without $100 \mathrm{ng} / \mathrm{ml} \mathrm{TRAIL}$ protein for $2 \mathrm{~h}$. Western blotting was used to evaluate the expression of apoptosis-associated cleaved caspase- 8 and cleaved caspase-3. (D) The immunocytochemistry results also indicated the activation of caspase- 8 and cleaved caspase-3 (scale bar, $50 \mu \mathrm{m}$ ). Statistically significant differences between the control and each indicated treatment group are presented as ${ }^{*} \mathrm{P}<0.01$ and ${ }^{* *} \mathrm{P}<0.001$. TRAIL, tumor necrosis factor-related apoptosis-inducing ligand; DR, death receptor; CQ, chloroquine; Amit, amitriptyline. 

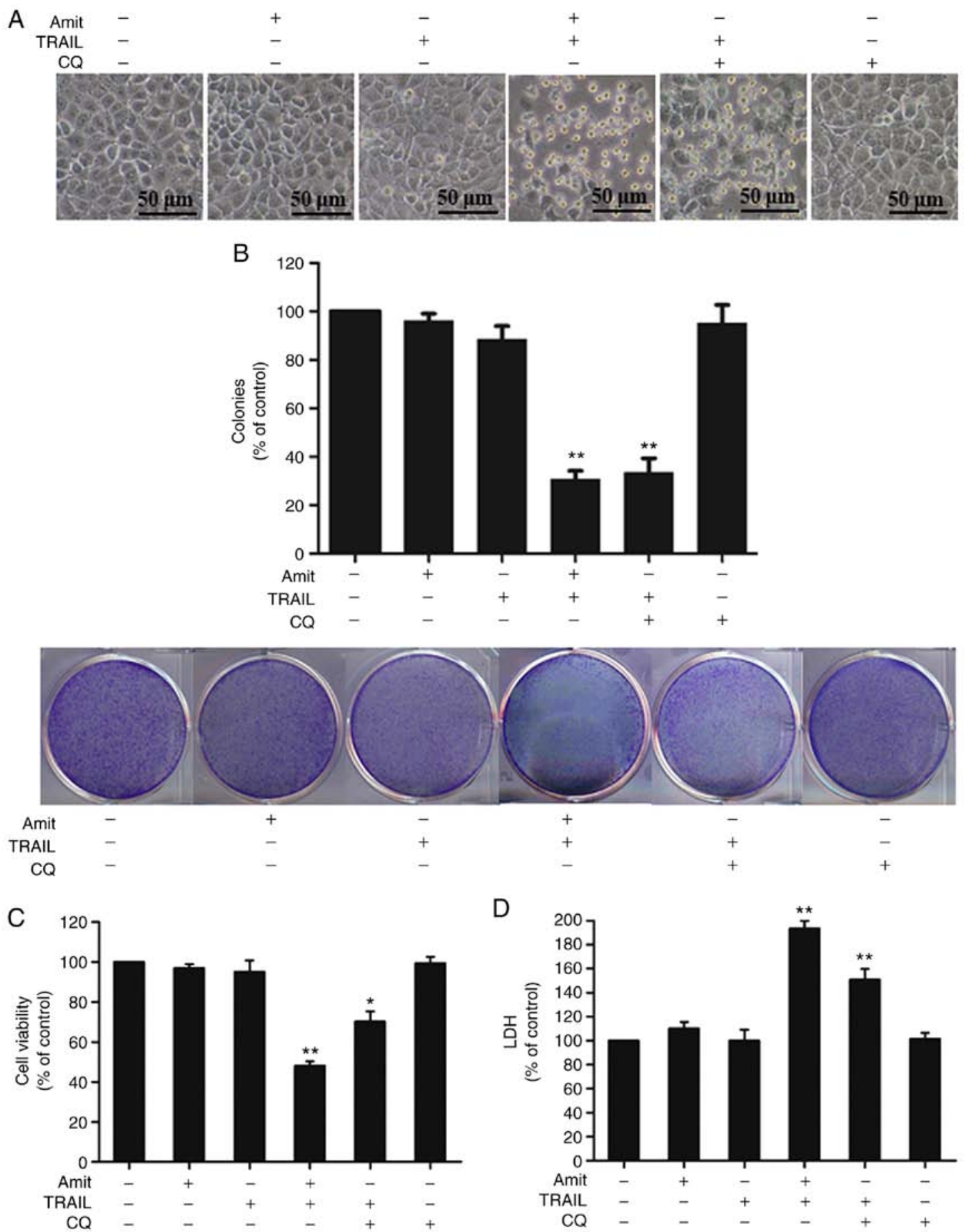

Figure 7. Blocking autophagy by amitriptyline aggravates TRAIL-mediated apoptosis. A549 cells were preincubated with or without CQ (20 $\mu$ M) and amitriptyline $(40 \mu \mathrm{M})$ for $12 \mathrm{~h}$ and finally, with or without $100 \mathrm{ng} / \mathrm{ml}$ TRAIL for $3 \mathrm{~h}$. (A) Cell morphology images were captured under light microscopy (magnification, x 100; scale bar, $50 \mu \mathrm{m}$ ). (B) Cell colonies were stained with crystal violet dye and the number of colonies were counted. (C) MTT assays were performed to display cell viability (bar graph). (D) Secretion of LDH into the collected supernatant. Statistically significant differences between the control and each indicated treatment group are presented as ${ }^{*} \mathrm{P}<0.01$ and $^{* *} \mathrm{P}<0.001$. TRAIL, tumor necrosis factor-related apoptosis-inducing ligand; $\mathrm{CQ}$, chloroquine; Amit, amitriptyline; LDH, lactate dehydrogenase.

In the present study, it was determined that small doses of amitriptyline with TRAIL were effective in increasing the number of A549 apoptotic cells compared to single treatments. The combined treatment with amitriptyline and TRAIL attenuated the TRAIL resistance of lung cancer cells, initiated the expression of the apoptotic caspase cascade, and, notably, upregulated DR4 and DR5 expression, leading to apoptosis.
The present study mainly investigated the roles of DR4 and DR5 in the combination effect and the mechanism of the upregulation of DR4 and DR5. Agonistic TRAIL-R antibodies are more attractive than TRAIL because they can target DR4 and DR5 to initiate TRAIL-induced apoptotic death in several types of tumors $(40,41)$. The upregulation of DR4 or DR5 by amitriptyline indicated the potential of a combination of amitriptyline and TRAIL/TRAIL-R antibodies. 
The present findings demonstrated that the genetic inhibitor of DR4 and DR5 decreased the effect of amitriptyline on TRAIL-mediated apoptosis. These results indicated that DR4 and DR5 were essential for the combined effect. Additionally, these findings revealed for the first time that amitriptyline promoted DR4 and DR5 expression via autophagy inhibition. Cancer cell death was promoted by autophagy inhibition, while autophagy played a cell-protective role in anticancer treatment $(49,50)$. Under such conditions, the aforementioned findings confirmed that amitriptyline increases autophagosome formation, indicated by LC3-II accumulation, and inhibits lysosomal fusion resulting in the accumulation of p62, causing the inhibition of autophagy flux by blocking autophagosome-lysosome fusion.

The combined effect of TRAIL with amitriptyline or CQ increased cell death unlike the individual treatments. The inhibition of autophagy by amitriptyline and the well-known autophagy inhibitor CQ resulted in DR4 and DR5 upregulation and improved TRAIL-mediated caspase-dependent cell death confirmed by the enhanced caspase cascade. Amitriptyline is a psychoactive TCA drug. In this study, only amitriptyline among the numerous antidepressant drugs was used to reveal the enhancing effect with TRAIL. Further studies using other antidepressant drugs are required to support or demonstrate the sensitization to TRAIL and anticancer effect by treatment of TCA drugs.

Collectively, these findings contributed to the mechanistic evidence that amitriptyline sensitized lung cancer cells to TRAIL and the sensitization was mediated through DR4 and DR5 upregulation and autophagy inhibition. These results provide an understanding of the anticancer effect of amitriptyline and suggest further evaluation is required to develop possible therapeutic regimens against lung cancer and cancer-associated depression.

\section{Acknowledgements}

Not applicable.

\section{Funding}

This study was supported by a grant from the National Research Foundation of Korea (NRF) funded by the Ministry of Education (grant. no. 2019R1A6A1A03033084).

\section{Availability of data and materials}

All datasets generated or analyzed during the present study are available from the corresponding author upon reasonable request.

\section{Authors' contributions}

KMAZ and SYP designed and performed the study, analyzed data and wrote the manuscript. Both authors have read and approved the final manuscript.

\section{Ethics approval and consent to participate}

Not applicable.

\section{Patient consent for publication}

Not applicable.

\section{Competing interests}

The authors declare that they have no competing interests.

\section{References}

1. Jemal A, Bray F, Center MM, Ferlay J, Ward E and Forman D: Global cancer statistics. CA Cancer J Clin 61: 69-90, 2011.

2. Siegel RL, Miller KD and Jemal A: Cancer statistics, 2018. CA Cancer J Clin 68: 7-30, 2018.

3. Ettinger DS, Akerley W, Borghaei H, Chang AC, Cheney RT, Chirieac LR, D'Amico TA, Demmy TL, Ganti AK, Govindan R, et al: Non-Small cell lung cancer. J Natl Compr Canc Netw 10: 1236-1271, 2012.

4. Kanitkar AA, Schwartz AG, George J and Soubani AO: Causes of death in long-term survivors of non-small cell lung cancer: A regional surveillance, epidemiology, and end results study. Ann Thorac Med 13: 76-81, 2018

5. Heinzmann K, Nguyen QD, Honess D, Smith DM, Stribbling S, Brickute D, Barnes C, Griffiths J and Aboagye E: Depicting changes in tumor biology in response to cetuximab monotherapy or combination therapy by apoptosis and proliferation imaging using ${ }^{18}$ F-ICMT-11 and ${ }^{18}$ F-FLT PET. J Nucl Med 59: 1558-1565, 2018.

6. Thomas PA: Stage IIIA N2 non-small-cell lung cancer: Current controversies in combined-modality therapy. Eur J Cardiothorac Surg 36: 431-432, 2009.

7. Nowak-Sliwinska P, Scapozza L and Altaba AR: Drug repurposing in oncology: Compounds, pathways, phenotypes and computational approaches for colorectal cancer. Biochim Biophys Acta Rev Cancer 1871: 434-454, 2019.

8. Jia Y, Yun CH, Park E, Ercan D, Manuia M, Juarez J, Xu C, Rhee K, Chen T, Zhang H, et al: Overcoming EGFR(T790M) and EGFR(C797S) resistance with mutant-selective allosteric inhibitors. Nature 534: 129-132, 2016.

9. Nesterov A, Ivashchenko Y and Kraft AS: Tumor necrosis factor-related apoptosis-inducing ligand (TRAIL) triggers apoptosis in normal prostate epithelial cells. Oncogene 21: 1135-1140, 2002.

10. Trivedi R and Mishra DP: Trailing TRAIL resistance: Novel targets for TRAIL sensitization in cancer Cells. Front Oncol 5: 69, 2015.

11. Marsters SA, Sheridan JP, Pitti RM, Huang A, Skubatch M, Baldwin D, YuanJ, Gurney A, Goddard AD, Godowski P and Ashkenazi A: A novel receptor for Apo2L/TRAIL contains a truncated death domain. Curr Biol 7: 1003-1006, 1997.

12. Jin CY, Moon DO, Lee JD, Heo MS, Choi YH, Lee CM, Park YM and Kim GY: Sulforaphane sensitizes tumor necrosis factor-related apoptosis-inducing ligand-mediated apoptosis through downregulation of ERK and akt in lung adenocarcinoma A549 cells. Carcinogenesis 28: 1058-1066, 2007.

13. Thorburn A, Behbakht K and Ford H: TRAIL receptor-targeted therapeutics: Resistance mechanisms and strategies to avoid them. Drug Resist Updat 11: 17-24, 2008.

14. Mérino D, Lalaoui N, Morizot A, Solary E and Micheau O: TRAIL in cancer therapy: Present and future challenges. Expert Opin Ther Targets 11: 1299-1314, 2007.

15. Hale AN, Ledbetter DJ, Gawriluk TR and Rucker EB III: Autophagy: Regulation and role in development. Autophagy 9: 951-972, 2013

16. Rouschop KM and Wouters BG: Regulation of autophagy through multiple independent hypoxic signaling pathways. Curr Mol Med 9: 417-424, 2009.

17. Thorburn A, Thamm DH and Gustafson DL: Autophagy and cancer therapy. Mol Pharmacol 85: 830-838, 2014.

18. Sui X, Chen R, Wang Z, Huang Z, Kong N, Zhang M, Han W, Lou F, Yang J, Zhang Q, et al: Autophagy and chemotherapy resistance: A promising therapeutic target for cancer treatment. Cell Death Dis 4: e838-e838, 2013.

19. ZinnahKMA andParkSY:Duloxetine enhances TRAIL-mediated apoptosis via AMPK-mediated inhibition of autophagy flux in lung cancer cells. Anticancer Res 39: 6621-6633, 2019. 
20. Di Rosso ME, Sterle HA, Cremaschi GA and Genaro AM: Beneficial effect of fluoxetine and sertraline on chronic stress-induced tumor growth and cell dissemination in a mouse model of lymphoma: Crucial role of antitumor immunity. Front Immunol 9: 1341, 2018.

21. Thaker PH, Han LY, Kamat AA, Arevalo JM, Takahashi R, Lu C Jennings NB, Armaiz-Pena G, Bankson JA, Ravoori M, et al: Chronic stress promotes tumor growth and angiogenesis in a mouse model of ovarian carcinoma. Nat Med 12: 939-944, 2006

22. Kim-Fuchs C, Le CP, Pimentel MA, Shackleford D, Ferrari D, Angst E, Hollande F and Sloan EK: Chronic stress accelerates pancreatic cancer growth and invasion: A critical role for beta-adrenergic signaling in the pancreatic microenvironment. Brain Behav Immun 40: 40-47, 2014.

23. Hasegawa $\mathrm{H}$ and Saiki I: Psychosocial stress augments tumor development through beta-adrenergic activation in mice. Jpn J Cancer Res 93: 729-735, 2002.

24. Fann JR, Fan MY and Unützer J: Improving primary care for older adults with cancer and depression. J Gen Intern Med 24 (Suppl 2): S417-S424, 2009.

25. Laird B, Colvin L and Fallon M: Management of cancer pain: Basic principles and neuropathic cancer pain. Eur J Cancer 44 1078-1082, 2008.

26. Frick LR and Rapanelli M: Antidepressants: Influence on cancer and immunity? Life Sci 92: 525-532, 2013

27. Zhang Z, Du X, Zhao C, Cao B, Zhao Y and Mao X: The antidepressant amitriptyline shows potent therapeutic activity against multiple myeloma. Anticancer Drugs 24: 792-798, 2013.

28. Cordero MD, Sánchez-Alcázar JA, Bautista-Ferrufino MR Carmona-López MI, Illanes M, Ríos MJ, Garrido-Maraver J, Alcudia A, Navas P and de Miguel M: Acute oxidant damage promoted on cancer cells by amitriptyline in comparison with some common chemotherapeutic drugs. Anticancer Drugs 21: 932-944, 2010.

29. Livak KJ and Schmittgen TD: Analysis of relative gene expression data using real-time quantitative PCR and the 2(-Delta Delta C(T)) method. Methods 25: 402-408, 2001.

30. Yuan X, Gajan A, Chu Q, Xiong H, Wu K and Wu GS: Developing TRAIL/TRAIL death receptor-based cancer therapies. Cancer Metastasis Rev 37: 733-748,2018.

31. Islam MA, Sooro MA and Zhang P: Autophagic regulation of p62 is critical for cancer therapy. Int J Mol Sci 19: 1405, 2018.

32. Wiley SR, Schooley K, Smolak PJ, Din WS, Huang CP, Nicholl JK, Sutherland GR, Smith TD, Rauch C, Smith CA, et al: Identification and characterization of a new member of the TNF family that induces apoptosis. Immunity 3: 673-682, 1995.

33. Walczak H, Miller RE, Ariail K, Gliniak B, Griffith TS, Kubin M, Chin W, Jones J, Woodward A, Le T, et al: Tumoricidal activity of tumor necrosis factor-related apoptosis-inducing ligand in vivo. Nat Med 5: 157-163, 1999.

34. Aggarwal BB, Bhardwaj U and Takada Y: Regulation of TRAIL-induced apoptosis by ectopic expression of antiapoptotic factors. Vitam Horm 67: 453-483, 2004.

35. Wang S: TRAIL: A sword for killing tumors. Curr Med Chem 17: 3309-3317, 2010

36. Chaudhary PM, Eby M, Jasmin A, Bookwalter A, Murray J and Hood L: Death receptor 5, a new member of the TNFR family, and DR4 induce FADD-dependent apoptosis and activate the NF-kappaB pathway. Immunity 7: 821-830, 1997.

37. Pan G, O'Rourke K, Chinnaiyan AM, Gentz R, Ebner R, Ni J and Dixit VM: The receptor for the cytotoxic ligand TRAIL. Science 276: 111-113, 1997.

38. Cretney E, Takeda K and Smyth MJ: Cancer: Novel therapeutic strategies that exploit the TNF-related apoptosis-inducing ligand (TRAIL)/TRAIL receptor pathway. Int J Biochem Cell Biol 39: 280-286, 2007.

39. Danial NN and Korsmeyer SJ: Cell death: Critical control points. Cell 116: 205-219,2004

40. Plummer R, Attard G, Pacey S, Li L, Razak A, Perrett R, Barrett M, Judson I, Kaye S, Fox NL, et al: Phase 1 and pharmacokinetic study of lexatumumab in patients with advanced cancers. Clin Cancer Res 13: 6187-6194, 2007.

41. Hotte SJ, Hirte HW, Chen EX, Siu LL, Le LH, Corey A, Iacobucci A, MacLean M, Lo L, Fox NL and Oza AM: A phase 1 study of mapatumumab (fully human monoclonal antibody to TRAIL-R1) in patients with advanced solid malignancies. Clin Cancer Res 14: 3450-3455, 2008.
42. Cheng H, Hong B, Zhou L, Allen JE, Tai G, Humphreys R, Dicker DT, Liu YY and El-Deiry WS: Mitomycin C potentiates TRAIL-induced apoptosis through p53-independent upregulation of death receptors: Evidence for the role of c-Jun N-terminal kinase activation. Cell Cycle 11: 3312-3323, 2012.

43. Dolloff NG, Mayes PA, Hart LS, Dicker DT, Humphreys R and El-Deiry WS: Off-target lapatinib activity sensitizes colon cancer cells through TRAIL death receptor up-regulation. Sci Transl Med 3: 86ra50, 2011.

44. Maiuri MC, Zalckvar E, Kimchi A and Kroemer G: Self-Eating and self-killing: Crosstalk between autophagy and apoptosis. Nat Rev Mol Cell Biol 8: 741-752, 2007.

45. Mizushima N, Levine B, Cuervo AM and Klionsky DJ: Autophagy fights disease through cellular self-digestion. Nature 451: 1069-1075, 2008.

46. Amin A, BajboujK, Koch A, Gandesiri M and Schneider-Stock R: Defective autophagosome formation in p53-null colorectal cancer reinforces crocin-induced apoptosis. Int J Mol Sci 16 $1544-1561,2015$

47. Wu YT, Tan HL, Huang Q, Kim YS, Pan N, Ong WY, Liu ZG, Ong $\mathrm{CN}$ and Shen HM: Autophagy plays a protective role during zVAD-induced necrotic cell death. Autophagy 4: 457-466, 2008.

48. White E: Autophagic cell death unraveled: Pharmacological inhibition of apoptosis and autophagy enables necrosis. Autophagy 4 : 399-401, 2008

49. Vucicevic L, Misirkic M, Janjetovic K, Vilimanovich U, Sudar E, Isenovic E, Prica M, Harhaji-Trajkovic L, Kravic-Stevovic T, Bumbasirevic $\mathrm{V}$ and Trajkovic V: Compound C induces protective autophagy in cancer cells through AMPK inhibition-independent blockade of Akt/mTOR pathway. Autophagy 7: 40-50, 2011.

50. Shen S, Zhang Y, Wang Z, Zhang R and Gong X: Bufalin induces the interplay between apoptosis and autophagy in glioma cells through endoplasmic reticulum stress. Int J Biol Sci 10: 212-224, 2014.

51. Klionsky DJ, Abdelmohsen K, Abe A, Abedin MJ, Abeliovich $\mathrm{H}$, Arozena AA, Adachi H, Adams CM, Adams PD and Adeli K: Guidelines for the use and interpretation of assays for monitoring autophagy (3rd edition). Autophagy 12: 1-222, 2016.

52. Gómez-Sánchez R, Yakhine-Diop SMS, Rodríguez-Arribas M, Bravo-San Pedro JM, Martínez-Chacón G, Uribe-Carretero E, de Castro DC, Pizarro-Estrella E, Fuentes JM and GonzálezPolo RA: mRNA and protein dataset of autophagy markers (LC3 and p62) in several cell lines. Data Brief 7: 641-647, 2016.

53. Mauthe M, Orhon I, Rocchi C, Zhou X, Luhr M, Hijlkema KJ, Coppes RP, Engedal N, Mari M and Reggiori F: Chloroquine inhibits autophagic flux by decreasing autophagosome-lysosome fusion. Autophagy 14: 1435-1455, 2018.

54. Nordstrøm LU, Sironi J, Aranda E, Maisonet J, Perez-Soler R, Wu P and Schwartz EL: Discovery of autophagy inhibitors with antiproliferative activity in lung and pancreatic cancer cells. ACS Med Chem Lett 6: 134-139, 2015.

55. Pan H, Wang Y, Na K, Wang Y, Wang L, Li Z, Guo C, Guo D and Wang X: Autophagic flux disruption contributes to Ganoderma lucidum polysaccharide-induced apoptosis in human colorectal cancer cells via MAPK/ERK activation. Cell Death Dis 10: 456, 2019.

56. Gasiorkiewicz BM, Koczurkiewicz-Adamczyk P, Piska K and Pękala E: Autophagy modulating agents as chemosensitizers for cisplatin therapy in cancer. Invest New Drugs 39: 538-563, 2020.

57. Nazim UM, Yin H and Park SY: Downregulation of c-FLIP and upregulation of DR- 5 by cantharidin sensitizes TRAIL-mediated apoptosis in prostate cancer cells via autophagy flux. Int J Mol Med 46: 280-288, 2020.

58. Park EJ, Min Kj, Choi KS, Kubatka P, Kruzliak P, Kim DE and Kwon TK: Chloroquine enhances TRAIL-mediated apoptosis through up-regulation of DR5 by stabilization of mRNA and protein in cancer cells. Sci Rep 6: 22921, 2016.

59. Shin GC,Kang HS,Lee AR and Kim KH: Hepatitis B virus-triggered autophagy targets TNFRSF10B/death receptor 5 for degradation to limit TNFSF10/TRAIL response. Autophagy 12: 2451-2466, 2016.

60. Twomey JD and Zhang B: Circulating tumor cells develop resistance to TRAIL-induced apoptosis through autophagic removal of death receptor 5: Evidence from an in vitro model. Cancers (Basel) 11: 94, 2019.

This work is licensed under a Creative Commons Attribution-NonCommercial-NoDerivatives 4.0 International (CC BY-NC-ND 4.0) License. 